\title{
Studying the Siberian Anthropocene: An Introduction
}

\author{
Andy Bruno | ORCID: 0000-0002-8723-324X \\ Associate Professor, College of Liberal Arts and Sciences, Department \\ of History, Northern Illinois University, DeKalb, IL, USA \\ Leading Research Fellow, Research Center "Human, Nature, and Technology," \\ School for Environmental and Social Studies, Tyumen State University, \\ Tyumen, Russian Federation \\ abruno2@niu.edu
}

The Anthropocene implies a planetary shift in the functioning of the systems that regulate life on Earth. Overwhelmed by the human impacts that have physically remade much of the planet's landscape and changed the chemistry of its air and water, its inhabitants find themselves in a predicament of multiple and overlapping environmental stresses that have pushed Earth into a new geological epoch. ${ }^{1}$ Unlike the Holocene, which began with the end of the last Ice Age approximately 11,700 years ago, the Anthropocene is of a much more recent provenance. Some scientists have argued for the significance of earlier human impacts such as the advent of fire or agriculture and others point to the transformations in nature use since the start of industrialization in Europe and North America in the nineteenth century. But the most popular proposal to date the start of the Anthropocene demarks the exponential explosion of anthropocentric pressures since the Second World War. This dating makes it coterminous with another novel notion of environmental studies- the Great Acceleration. ${ }^{2}$

From a scientific standpoint, the concept of the Anthropocene has rapidly gained ground in the twenty-first century. It has gone from an ad-hoc notion bandied about in a conference presentation by renowned chemist Paul Crutzen to a proposal by a working group of the International Commission on

1 Julia Adeney Thomas, Mark Williams, and Jan Zalasiewicz, The Anthropocene: A Multidisciplinary Approach (London: Polity Press, 2020).

2 J. R. McNeill and Peter Engelke, The Great Acceleration: An Environmental History of the Anthropocene (Cambridge, MA: Harvard University Press, 2016). 
Stratigraphy to formally establish a new epoch. ${ }^{3}$ While convictions about the human capacity to alter not only the biology of the planet but also its geology predate even the most popular start date for the Anthropocene, none of these previous conjectures have come as close to being incorporated into mainstream scientific practice. If the Anthropocene is formalized, it will mean that for the first time in recorded human history a new geological epoch has begun. The fact that the Anthropocene has been wrought by the tremendous scale of human activities primarily points to the unsettling precarity of the present and future, despite occasional misguided attempts to again proclaim human transcendence over nature in these new conditions. ${ }^{4}$

The unifying vision of global environmental history of the recent past implied by the Anthropocene has produced an outpouring of enthusiasm from scholars in the humanities and social sciences. In a sense it has supplanted "modernity" as a catch-all concept for the character of the contemporary world, but one that focuses on the rootedness of human beings in a material world amid rapid transformation rather than the cultural and social implications stemming from the pursuit of transcending the past. Thousands of scholarly articles and books have appeared with the word "Anthropocene" in the title and there are now multiple journals devoted to it. ${ }^{5} \mathrm{~A}$ group of interdisciplinary scholars have also delineated between the overlapping spheres of environmental history and Anthropocene history. They distinguish the latter by "the unprecedented novelty of the predicament at its heart," "attentiveness to enormous scales of time and space," "engagement with Earth System science," and "a willingness to wrestle with 'the human' as a planetary force." Not all historical scholarship that engages with the Anthropocene necessarily aligns with these distinctions, but they are helpful for seeing what might be new in this approach to studying environmental pasts.

3 Will Steffen, Paul J. Crutzen, and John R. McNeill, "The Anthropocene: Are Humans Now Overwhelming the Great Forces of Nature?" Ambio 36, no. 8 (December 2007): 614-621.

4 Christophe Bonneuil and Jean-Baptiste Fressoz, The Shock of the Anthropocene: The Earth, History and Us (London: Verso, 2015); Jedediah Purdy, After Nature: A Politics for the Anthropocene (Cambridge, MA: Harvard University Press, 2015); Jeremy Davies, The Birth of the Anthropocene (Berkeley: University of California Press, 2016); Roy Scranton, Learning to Die in the Anthropocene: Reflections on the End of a Civilization (San Francisco: City Light Books, 2015); W. John Kress and Jeffrey Stine, eds., Living in the Anthropocene: Earth in the Age of Humans (Washington, DC: Smithsonian Books, 2017); Duncan Kelly, Politics and the Anthropocene (Cambridge: Polity Press, 2019); Eva Horn and Hannes Bergthaller, The Anthropocene: Key Issues for the Humanities (London: Routledge, 2020); Dipesh Chakrabarty, The Climate of History in a Planetary Age (Chicago: University of Chicago Press, 2021).

5 The journals with "Anthropocene" in the title include Anthropocene, The Anthropocene Review, Anthropocenes: Human, Inhuman, Posthuman; and Elementa: Science of the Anthropocene.

6 Thomas, Williams, and Zalasiewicz, The Anthropocene, 133. 
If engagement with the concept of the Anthropocene has proliferated quickly, criticism of the notion has also been fierce and relentless. Perhaps such pushback has been almost dialectically predetermined, akin to earlier postmodern negations of modernism and modernity. The etymological allusions of the name Anthropocene as the "age of humans" speaks to the heart of the problem. Critics of the term have underscored the misplaced agency of human beings implied by labeling the era after us and the muddled view on causation that emerges from focusing on a collective humanity. The question of why the planet has entered the Anthropocene, some contend, is obscured by the choice of a universalizing concept that appeals to the entire species as opposed to privileged groups (the wealthy, Western, and white, for instance) and the injurious systems they've built (capitalism, colonialism, uncontrolled technology, racism, sexism, etc.). Why not speak of the Capitalocene (which foregrounds the role of capitalism in imperiling the planet), the Plantationocene (which roots the predicament in the agricultural transformations that came with racial slavery), or the Carbocene (which affords agency to the very chemical that is forcing climate disruption) instead of the Anthropocene? ${ }^{7}$ Or would any replacement for the term prompt just as many ripostes?

One possibility for weaving a path between the insights afforded by the notion of the Anthropocene and the perils of applying a totalistic view that flattens difference and obfuscates causation is to use the concept to invite reflection on the environmental connections between the sweep of global change and the local histories of place. There have been several efforts to write Anthropocene histories of different continents, countries, regions, landscapes, and water bodies. ${ }^{8}$ Others have addressed partial and marginalized experiences within the Anthropocene to better understand the diversity of recent engagement with the natural world. "A billion Black Anthropocenes or none" as Kathryn Yusoff polemically declares. ${ }^{9}$ Such scholarship on

7 Andreas Malm and Alf Hornborg, "The Geology of Mankind? A Critique of the Anthropocene Narrative," The Anthropocene Review 1, no. 1 (2014): 62-69; Timothy James LeCain, "Against the Anthropocene: A Neo-Materialist Perspective," International Journal for History, Culture and Modernity 3, no.1 (April 2015): 1-28; Jason Moore, ed., Anthropocene or Capitalocene? Nature, History, and the Crisis of Capitalism (Oakland, CA: PM Press, 2016).

8 Gabrielle Hecht, "Interscalar Vehicles for an African Anthropocene: On Waste, Temporality, and Violence," Cultural Anthropology 33, no. 1 (2018): 109-141; Elizabeth Chatterjee, "The Asian Anthropocene: Electricity and Fossil Fuel Developmentalism," Journal of Asian Studies 79, no. 1 (February 2020): 3-24; David Lipset, "Place in the Anthropocene: A Mangrove Lagoon in Papua New Guinea in the Time of Rising Sea-Levels," HAU:Journal of Ethnographic Theory 4, no. 3 (2014): 215-43.

9 Kathryn Yusoff, A Billion Black Anthropocenes of None (Minneapolis: University of Minnesota Press, 2018). 
particular Anthropocene stories have also begun to appear in the field of Russian studies. ${ }^{10}$

This two-part special issue of The Soviet and Post-Soviet Review brings together scholars who engage with the perspective of the Anthropocene to enrich their studies of the environmental history of Siberia. Notably, none of them takes the Anthropocene at face value, nor do they use it as the exclusive focus of their analysis. Instead, the articles discuss the Anthropocene to reflect on comparative and transnational trends that connect to local developments, including the incorporation of Indigenous peoples into Soviet economic programs and attempts to make Siberia a template for novel forms of human relations with nature. The Siberian Anthropocene in the authors' collective rendering highlights both Soviet distinctiveness as well as their case's alignment with global trends.

The first two articles appear here, while issue 1 of 2022 will feature the remaining ones. Concerned with a longing to harmonize development and ecology, Roman Bugaev, Mikhail Piskunov, and Timofey Rakov explore the greening initiatives in the Akademogorodok section of Novosibirsk in the 1950s and 1960s in "Footpaths of the Late-Soviet Environmental Turn: The 'Forest City' of Novosibirsk's Akademgorodok as a Sociotechnical Imaginary." They ambitiously link the alternative ecological relationships envisioned by the settlement's planners to a countertrend of the Anthropocene that involves a search for urban lifestyles more expressly embedded in the natural environment. Evolving views on the relationship between humans and natural resources also feature in "The North of Western Siberia in the Socio-Economic Space of the USSR: Shifting Models of Nature Use." Evgenii Gololobov analyzes the history of how a zone in the northwestern part of Siberia became a terrain of hydrocarbon exploitation in the late Soviet period and unearths the key role played by a deepening perspective about human migrants as being a flexible resource in the use of nature. This shift toward an oil and gas economy also marginalized the pre-existing population of the region.

The articles for the next issue expand on this theme of Indigenous experience. In "An Indigenous Anthropocene: Subsistence Colonization and Ecological Imperialism in the Soviet Arctic in the 1920s and Early 1930s," Igor

10 Andy Bruno, "Polluted Pearl of the North: Lake Imandra in the Anthropocene" in David Moon, Nicholas Breyfogle, and Alexandra Bekasova, eds., Place and Nature: Essays in Russian Environmental History (Cambridgeshire: White Horse Press, 2021), 69-91; Alec Brookes and Elena Fratto, "Toward a Russian Literature of the Anthropocene," Russian Literature 114-115 (2020): 1-22. 
Stas reveals how a program of economic colonization sought active participation of Indigenous populations in reforming their systems of nature use, though heavy industry eventually overshadowed this bout of ecological imperialism. Mariia Koskina also examines the place of Indigenous cultures in Soviet economic transformation in "Ancient Bogatyr to Electric River: The Modernized Mythology of the Yenisei." She shows how Soviet industrialists during the construction of the Krasnoyarsk Dam in the Khrushchev and Brezhnev eras appropriated Indigenous myths in their efforts to narrate the meaning of development.

Taken together, several themes emerge from these articles. The significance of Indigenous cultures for the emergence of the Anthropocene is one of them. Part of the story of Siberian history in the Soviet period was overwhelming northern peoples with migrants pursuing radically different ways of living on the land. The articles remind us that Indigenous cultures were not simply supplanted by the industrial gusto of the Soviets but found subtle ways to influence and interact with the transformed world. Relatedly, the articles in this special issue interrogate some of the mythologies of development, showing the intricacies of how various actors involved in construction projects made sense of their place not only in the Soviet system but within the broader future trajectory of humanity. Scientists in particular occupied multifaceted roles as both promoters of development and visionaries of sustainability. Finally, and perhaps most significantly, the articles address countertrends and alternative possibilities of the Anthropocene. Green landscapes in non-capitalist societies, Indigenous economic livelihoods retooled for the modern era, attention to animate and inanimate engagement from the non-human world, and views of human beings as a malleable part of nature emerge in these studies of Siberia's Anthropocene history.

\section{Acknowledgement}

The introduction to this special issue was supported by a grant from the Russian Science Foundation (project № 20-68-46o44), "Imaginary Anthropocene: Environmental Knowledge Production and Knowledge Transfers in Western Siberia in the Twentieth and Twenty-First Centuries." 